\title{
Accelerated Non-linear Destruction of the Earth's Crust
}

\author{
E.V. ARTYUSHKOV \\ United Institute of Physics of the Earth, B. Gruzinskaya 10, Moscow 123810, Russia
}

(Revised 3 January 2001)

\begin{abstract}
The upper part of the Earth-the lithospheric layer, $\sim 100 \mathrm{~km}$ thick, is rigid. Segments of this spherical shell-lithospheric plates are drifting over a ductile asthenosphere. On the continents, the lithosphere includes the Earth's crust, $\sim 40 \mathrm{~km}$ thick, which is underlain by peridotitic rocks of the mantle. In most areas, at depths $\sim 20-40 \mathrm{~km}$ the continental crust is composed of basalts with density $\sim 2900 \mathrm{~kg} \mathrm{~m}^{-3}$. At temperature and pressure typical for this depth, basalts are metastable and should transform into another assemblage of minerals which corresponds to garnet granulites and eclogites with higher densities $3300-3600 \mathrm{~kg} \mathrm{~m}^{-3}$. The rate of this transformation is extremely low in dry rocks, and the associated contraction of basalts evolves during the time $\geq 10^{8}$ a. To restore the Archimede's equilibrium, the crust subsides with a formation of sedimentary basins, up to $10-15 \mathrm{~km}$ deep.

Volumes of hot mantle with a water-containing fluid emerge sometimes from a deep mantle to the base of the lithosphere. Fluids infiltrate into the crust through the mantle part of the lithosphere. They catalyze the reaction in the lower crust which results in rock contraction with a formation of deep water basins at the surface during $\sim 10^{6}$ a. The major hydrocarbon basins of the world were formed in this way. Infiltration of fluids strongly reduces the viscosity of the lithosphere, which is evidenced by narrow-wavelength deformations of this layer. At times of softening of the mantle part of the lithosphere, it becomes convectively replaced by a hotter and lighter asthenosphere. This process has resulted in the formation of many mountain ranges and high plateaus during the last several millions of years. Softening of the whole lithospheric layer which is rigid under normal conditions allows its strong compressive and tensile deformations. At the epochs of compression, a large portion of dense eclogites that were formed from basalts in the lower crust sink deeply into the mantle. In some cases they carry down lighter blocks of granites and sedimentary rocks of the upper crust which delaminate from eclogitic blocks and emerge back to the crust. Such blocks of upper crustal rocks include diamonds and other minerals which were formed at a depth of $100-150 \mathrm{~km}$.
\end{abstract}

\section{INTRODUCTION}

A predominant part of the population of the Earth is living on the continents. The continental Earth's crust is the major source of mineral resources. On the other hand, its evolution is associated with destructive earthquakes and volcanic eruptions. Hence a knowledge on the structure and basic regularities of evolution of continental crust is of great importance. 
Over most of the continents, the continental crust is $\sim 40 \mathrm{~km}$ thick. It includes the upper-granitic and lower-basaltic layers, $\sim 20 \mathrm{~km}$ thick each (Fig. 1). The basaltic layer is underlain by the peridotitic rocks of the Earth's mantle which are denser than the crust. The crust and uppermost mantle form a rigid lithospheric layer. Over most of the continental areas, where the heat flow from the Earth's interior is low, the lithospheric thickness is $\sim 100-200 \mathrm{~km}$. Due to a temperature increase with depth, a strong decrease in mantle viscosity occurs below the lithosphere-in the low-viscosity asthenospheric layer.

The major advances in solid Earth sciences of the last third of the 20th century were associated with the origination of plate tectonics. According to this concept, the lithosphere is broken into large blocks-lithospheric plates, thousands of kilometers in size, which are drifting over the asthenosphere as rotating pieces of rigid spherical shell. Plate tectonics was very successful in a kinematic description of continental drift. It gave a good explanation for the formation of new oceanic crust by sea floor spreading at divergent boundaries of lithospheric plates on the oceanic floor, e.g. along the axis of the Atlantic ocean. Plate tectonics adequately explained a growth of chains of volcanic islands above the plates of dense oceanic lithosphere sinking (subducting) deeply into the mantle on active oceanic margins, e.g. the Japan and Aleutian islands. However, a direct application of plate tectonics to dynamics of the crust within the continental areas meets serious difficulties.

According to plate tectonic interpretation, vertical crustal movements on the continents should be caused by horizontal plate motions. The Earth's crust is less dense than the mantle. To restore the Archimede's equilibrium, strong thinning by extension of the crust with a constant thickness must result in its subsidence with a formation of sedimentary basins, such as those in West Siberia, Persian Gulf and North Sea (McKenzie, 1978). An intense thickening of this layer by compression will produce the crustal uplift and the formation of high mountain ranges and plateaus such as the Alps, Himalayas, Tibet and Rocky mountains (Miyashiro et al., 1982). However,

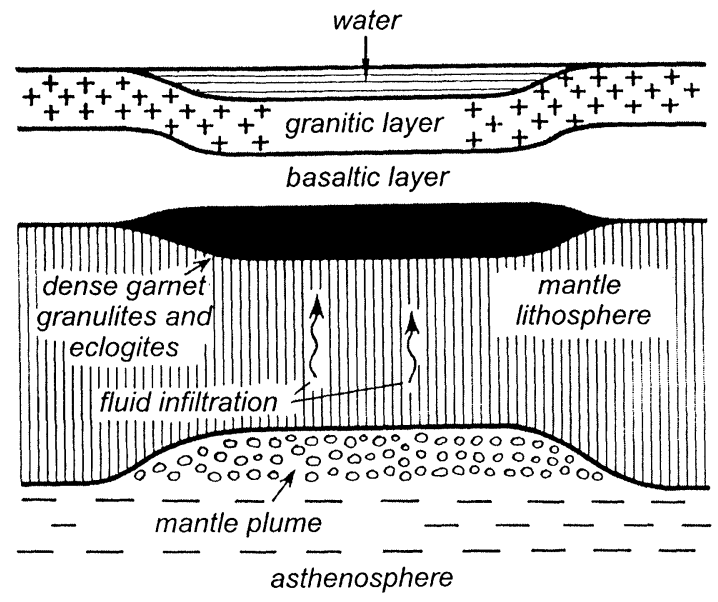

FIGURE 1 Crustal subsidence with a formation of a deep water basin due to a transformation of basalts in the lower crust into denser garnet granulites and eclogites. Rapid transformation of rocks occurs under infiltration into the lower crust of fluids from a small plume of heated mantle at the base of the lithosphere.

as follows from a large volume of data, a predominant part of sedimentary basins was actually formed without strong extension (Artyushkov, 1983; 1993), while most of the present high mountains and plateaus originated long after the end of compression (Artyushkov and Hofmann, 1998).

\section{FORMATION OF DEEP SEDIMENTARY BASINS DUE TO CONTRACTION OF BASALTS IN THE LOWER CRUST}

A section across the West Siberian basin which is the largest sedimentary basin of the world is shown in Fig. 2. The crustal subsidence took place in the basin during the last several hundreds of million years. In section of Fig. 2, the basin is up to $9 \mathrm{~km}$ deep. To produce a subsidence of such a scale by extension, the crust should be gradually stretched by $\sim 1.5$ times. However, in Fig. 2, the sedimentary strata are continuous across the West Siberian basin which precludes intensive stretching of the underlying crystalline part of the crust. Then to ensure the subsidence, a density increase should have occurred in the crust and/or mantle. 


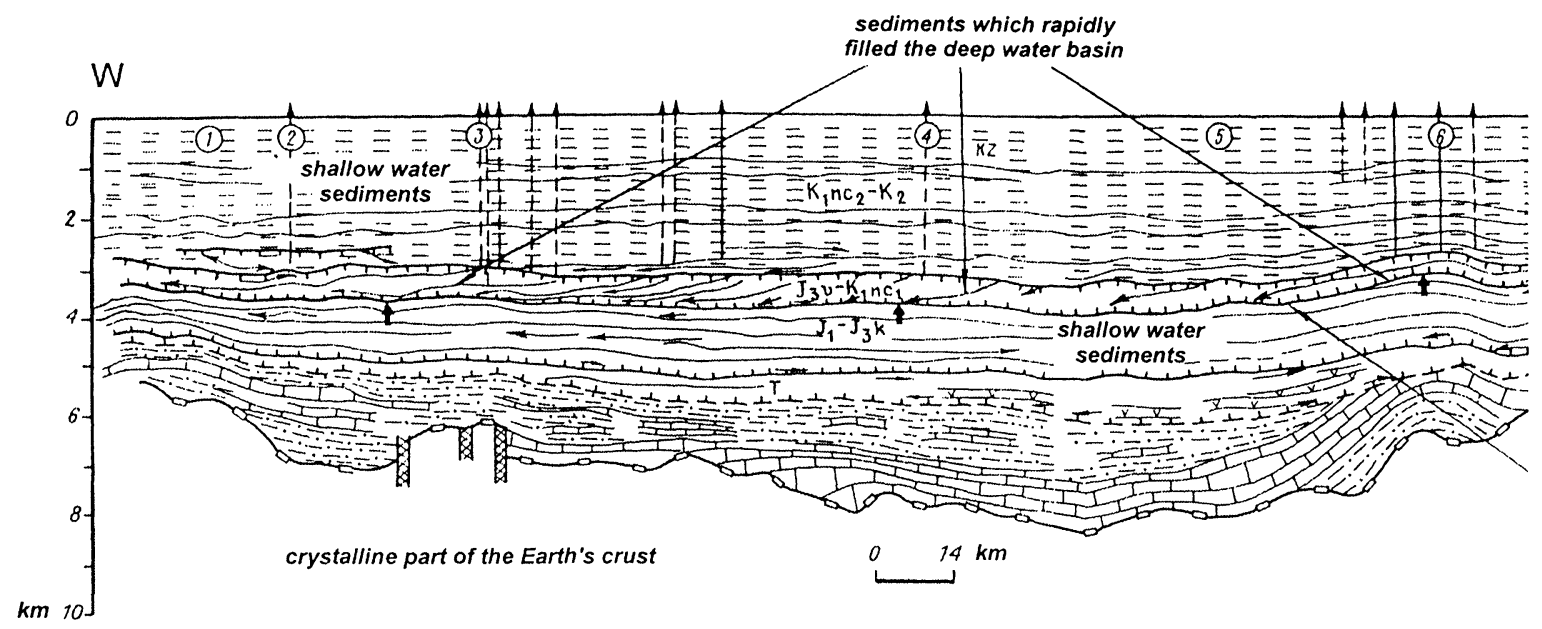

FIGURE 2 Seismic profile across the northern part of the West Siberian basin. A continuity of the strata can be traced across the basin which precludes significant extension of the underlying part of the lithosphere during the subsidence. Arrows indicate the boundary between shallow water deposits and deep water sediments which began to form after the rapid subsidence 150 million years ago.

It can be shown that thermoelastic contraction could not ensure the observed subsidence. A considerable density increase necessary to produce a strong subsidence could be ensured only by a change in the mineralogical composition in basaltic rocks in the lower part of the crust. The density of basalts is about $2900 \mathrm{~kg} \mathrm{~m}^{-3}$. At temperature and pressure typical for this depth, basalts are metastable and should transform into another assemblages of minerals which correspond to rocks called garnet granulites and eclogites. These rocks include a large volume of garnet with a high density $\sim 4400 \mathrm{~kg} \mathrm{~m}^{-3}$. As a result, mean densities of garnet granulites and eclogites are $3300-3600 \mathrm{~kg} \mathrm{~m}^{-3}$ which is up to $\sim 20 \%$ higher than the density of basalts. At the Archimede's equilibrium of the Earth's crust floating on the mantle, contraction by $10-20 \%$ in a layer of basalts, $15 \mathrm{~km}$ thick, is sufficient to produce a sedimentary basin, $7-13 \mathrm{~km}$ deep. Under dry conditions, the transformation of basalts into denser rocks evolves extremely slowly, and the associated formation of deep sedimentary basins proceeds for $\geq 10^{8}$ years. At certain epochs, episodes of very rapid crustal subsidence occurred in some sedimentary basins. For example, 150 million years ago, a basin with a depth of water $0.5-1 \mathrm{~km}$ was formed on a shallow water shelf of West Siberia during $\sim 1$ million years (Artyushkov and Baer, 1986). Filling of this basin with sediments and the additional crustal subsidence under their load increased the magnitude of the subsidence by $\sim 3$ times compared to the initial depth of water. An increase in the rate of crustal subsidence by two orders of magnitude required a corresponding increase in the rate of contraction of basalts in the lower crust. This can by produced by two factors: heating of rocks by $\sim 200^{\circ} \mathrm{K}$ or the appearance of a small amount of fluids $\left(\mathrm{H}_{2} \mathrm{O}+\mathrm{CO}_{2}\right)$ which catalyzes the reaction. Heating of the lithosphere usually occurs due to an increase in the heat flow from the underlying asthenosphere. In the lithosphere, $\geq 100 \mathrm{~km}$ thick, this requires tens of million years at least. A similar time is necessary to release water from hydrous minerals in the lower crust by their heating from the asthenosphere. Hence thermal effects could not be responsible for strong subsidence of a short duration $\sim 1$ million years. Under these circumstances, infiltration of fluids into basaltic rocks of the lower crust from the asthenosphere was necessary to cause a drastic increase in the rate of their transformation into denser rocks (Artyushkov et al., 1991).

The rapid subsidence in West Siberia was preceded by a slight crustal uplift $(\sim 100 \mathrm{~m})$ of a short duration $\sim 1$ million years. This as an indication of rapid 
density decrease in the underlying asthenosphere. It required convective replacement of the upper part of this layer, several tens of kilometers thick, by a hotter material which emerged from the depth (Fig. 1). This anomalous mantle volume (which is commonly called "mantle plume") was most probably the source of fluids that penetrated into the lower crust of West Siberia and caused contraction of basalts and the rapid crustal subsidence 150 million years ago.

Rapid subsidence of the described type sometimes occurred in many other sedimentary basins within the continents. This happened, e.g. in the West Texas basin $\sim 300$ million years ago, in the Timan-Pechora, Volga-Urals and Peri-Caspian basins in the east of East Europe 370 million years ago. Rapid subsidences were usually preceded by slight crustal uplifts, which in many cases were associated with a slight synchronous volcanism of mantle origin. Melting of rocks is enhanced by both an increase in temperature and a presence of fluids. Hence volcanism is another indication of emergence of heated and fluid-containing mantle plumes to the base of the lithosphere before rapid subsidences.

Infiltration of fluids from the mantle into the crust in sedimentary basins has been recently demonstrated using the geochemical data. In basins where rapid crustal subsidence had taken place, the isotopic ratios of rare Earth elements, the samarium to neodymium one in particular, are typical of the Earth's mantle rather than of the crustal layer (Pisotsky, 1999).

\section{ORIGIN OF HYDROCARBON BASINS}

The above-mentioned sedimentary basins are among the major hydrocarbon basins of the world. Giant oil and gas fields are located in them only within the areas of rapid crustal subsidence or just near to these areas. There are no large fields in the adjacent sedimentary basins where only a slow crustal subsidence took place. The same regularity is typical of the other large hydrocarbon basins. This can be illustrated, e.g. by the Persian Gulf area (Fig. 3). Numerous giant fields (in black) occur in the region where rapid crustal subsidences took place. Only three fields are located outside this region. However, they are close to its

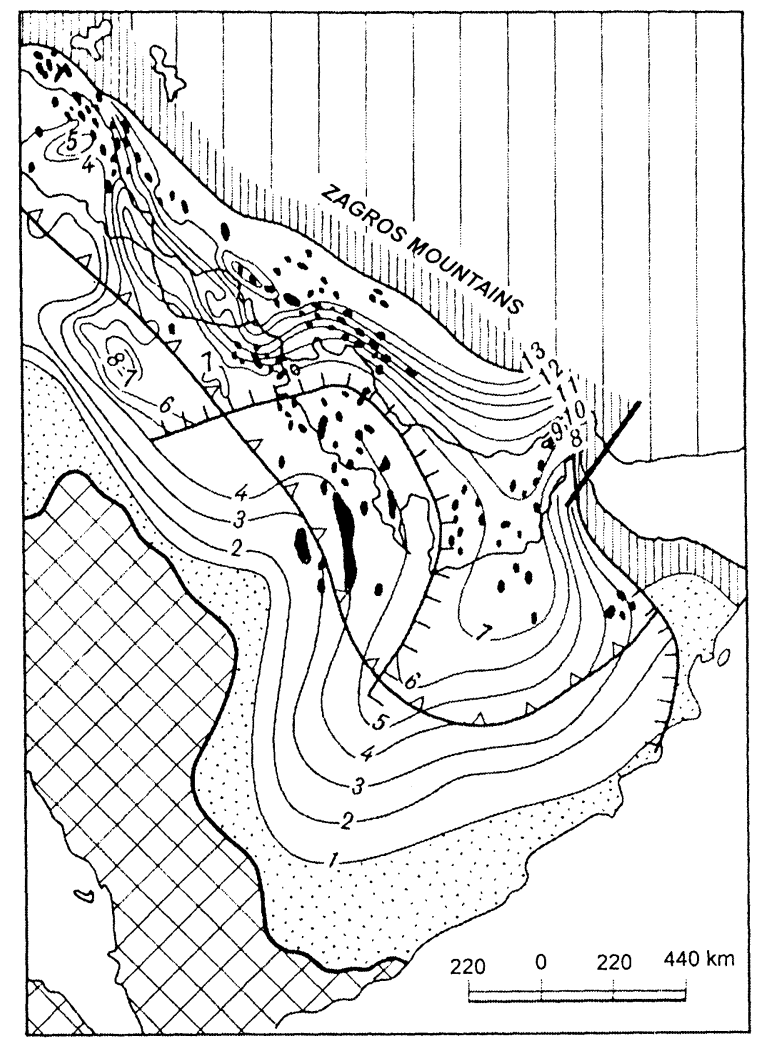

FIGURE 3 Giant oil and gas fields of the Persian Gulf area (in black). The area where rapid crustal subsidences took place is bounded by a toothed line in the south-west and by the Zagros mountains in the north-east. Numbers at the curved lines indicate the thickness of sediments $(\mathrm{km})$. Hydrocarbon fields predominantly occur within the area of rapid subsidence. Only three fields are located outside this area near to its south-western boundary. They could be formed due to a lateral migration of hydrocarbons from the areas of rapid subsidence.

boundary, and hydrocarbons could have reached the fields by lateral migration from the region of rapid subsidence.

The occurrence of giant hydrocarbon fields in the areas of rapid crustal subsidence is due to a combination of several factors (Artyushkov and Baer, 1986, 1987). First, the subsidence produces isolated or semi-isolated deep water basins with very favorable conditions for accumulation and preservation of unoxidized organic matter at the basin floor where water remains stagnant. Second, a strong increase in the heat flow from the Earth's interior occurs after rapid subsidences. This ensures a transformation of organic matter into oil and gas at 
shallow depth. Third, a strong decrease in crustal rigidity takes place at times of rapid subsidence (see next section). This allows narrow-wavelength deformations of the crystalline part of the crust under the sedimentary cover. In the overlying sediments, vertical displacements of the crystalline crust produce numerous upwarps-domes and ranges, several hundreds of meters high, where oil and gas are accumulating (see Fig. 2). As a result, regions of rapid subsidence become much more prolific than basins where only a slow crustal subsidence took place. This is a good criterion for discovery of new hydrocarbon basins, as well as new giant fields in the oil and gas basins which are already under explorations.

\section{STRONG SOFTENING OF THE LITHOSPHERE DUE TO INFILTRATION OF FLUIDS FROM THE ASTHENOSPHERE}

Surface loads produce bending of elastic plates. The characteristic width of their flexure $(L)$ increase with the plate thickness $(d)$ as $L_{\mathrm{km}} \sim 9\left(d_{\mathrm{km}}\right)^{3 / 4}$. In regions with a low heat flow $\sim 40 \mathrm{~mW} \mathrm{~m}^{-2}$ the continental lithosphere includes an elastic core, $50-80 \mathrm{~km}$ thick (Burov and Diament, 1995). Bending of such a lithosphere under surface and subsurface loads occurs in regions, $L \sim 170-240 \mathrm{~km}$ wide. It appears that during the rapid subsidences the lithosphere was bent by $3-10 \mathrm{~km}$ in regions which are only $20-40 \mathrm{~km}$ wide (Artyushkov and Mörner, 1997; 1998). A typical seismic section is shown in Fig. 4. The slope ab bounds a deep basin to the north of the Western Caucasus. The initial downwarping by $\sim 1 \mathrm{~km}$ occurred during $\sim 1$ million years about 33 million years ago. In the process of the following basin filling with sediments, the height of the slope increased to $3.6 \mathrm{~km}$. The seismic profile crosses the slope at an angle, so the actual slope width is smaller than in Fig. 4 (about $30 \mathrm{~km}$ ). Taking $L \sim 30$, we find that the thickness of the elastic core in the lithosphere is $d \sim 5 \mathrm{~km}$, i.e. the elastic layer practically disappears and the lithosphere becomes ductile. Similar lithospheric deformations occurred during rapid crustal subsidences and following $\sim 10$ million years in many other sedimentary basins, e.g. in the Peri-Caspian basin to the north of the Caspian Sea, and in deep basins which bound the Carpathians and Urals. They evidence strong temporary softening of the lithospheric layer. This explains why numerous domes and ranges which are good traps for oil and gas arise in hydrocarbon basins at times of rapid subsidence.

Rapid crustal subsidence due to rock contraction in the lower crust is triggered by infiltration of fluids from the asthenosphere into the lithosphere. Since lithospheric softening also occurs at the epochs of rapid subsidence, this phenomenon can be supposed to also result from infiltration of fluids from the asthenosphere. A drastic decrease in the strength and viscosity of metals under infiltration of active fluids which decrease the surface energy at the boundaries between the crystals was discovered long ago (Rebinder and Venström, 1937). Later it has been found to be typical of many other polycrystalline media including rocks of the Earth's crust and mantle (see Rutter, 1983 for review). A strong decrease in viscosity results from a change in the mechanism of deformation of crystals. Rapid diffusion of ions through thin films of fluid between the crystals from places with high stresses to those with low stresses produces recrystallization with a change of shape of crystals ("pressure solution creep"). Rapid narrowwavelength deformations of the lithosphere show that the effect of Rebinder sometimes happens in this layer on a macroscale. Surficially active fluids can be, e.g. water and carbon dioxide.

\section{RECENT FORMATION OF HIGH MOUNTAINS AND PLATEAUS DUE TO SOFTENING OF MANTLE LITHOSPHERE AND ITS CONVECTIVE REPLACEMENT BY THE ASTHENOSPHERE}

A large part of the continents is covered by mountain ranges and plateaus. They were predominantly formed during the last 3-5 million years, while during the preceding $\sim 200$ million years most of continental areas were nearly flat (Artyushkov and Hofmann, 1998). For example, the Tibetan plateau, $4-4.5 \mathrm{~km}$ 


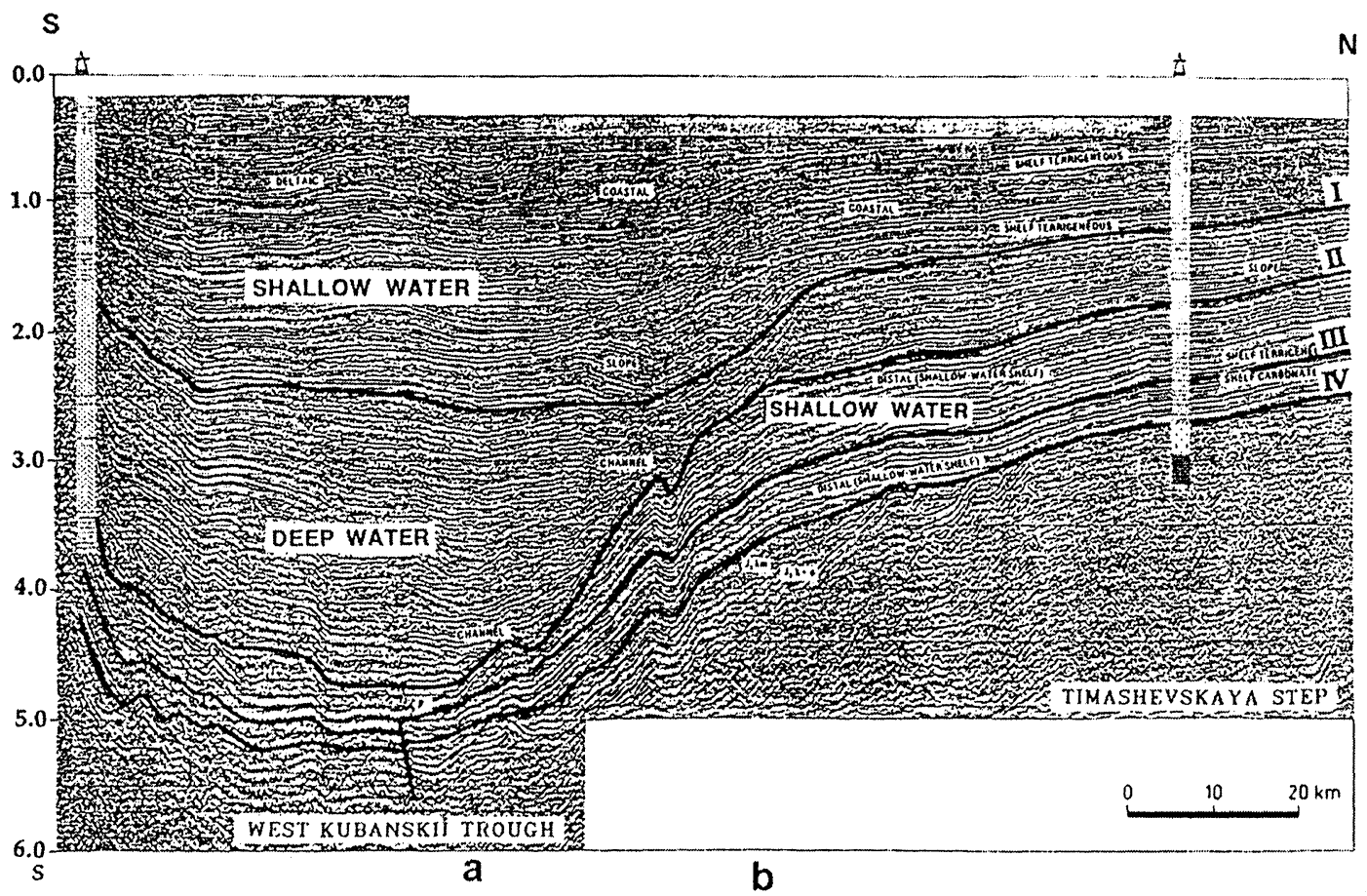

FIGURE 4 Steep flexure (ab), $3.6 \mathrm{~km}$ high, of the deposits on the northern margin of deep sedimentary basin to the north of the Western Greater Caucasus. Two-way travel time (s) of seismic waves is shown along the vertical axis. One second approximately corresponds to $1.6 \mathrm{~km}$ of depth. Rapid change from shallow water sediments to deep water ones, which happened about 33 million years ago, occurs at layer II.

high, was at $\leq 1 \mathrm{~km}$ above sea level 3.5 million years ago (Li Jijun et al., 1995). Over most of the areas, rapid crustal uplift occurred without compression and thickening of the curst. Hence it required a density decrease in the mantle.

The mantle part of the lithosphere is cooler and denser than the underlying hot asthenosphere with temperature $T \sim 1300^{\circ} \mathrm{C}$. This ensures a possibility of convective instability at the lithosphere-asthenosphere boundary with replacement of mantle lithosphere by the asthenosphere and strong uplift of the overlying crust. No intensive uplift, however, occurred over most of continental areas during $\sim 200$ million years before the onset of rapid recent crustal uplift. This shows that the viscosity of mantle lithosphere is extremely high under normal conditions, which precludes the development of convective instability.

Intensive crustal uplift during the last 3-5 million years indicates rapid convective replacement by a hot and light asthenosphere of the whole mantle lithosphere in some regions or of its considerable part in another ones (Fig. 5). This indicates a drastic viscosity decrease in the mantle lithosphere due to infiltration of fluids from small mantle plumes which emerged recently to the base of the lithosphere (Artyushkov and Hofmann, 1998). Rapid ascent from a deep mantle of fluid-containing plumes which occurs synchronously beneath different continents is a new

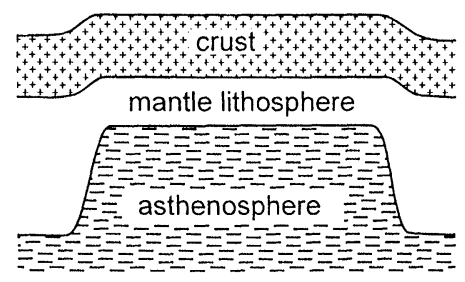

FIGURE 5 Replacement of the lower part of mantle lithosphere by a less dense asthenosphere which produces the crustal uplift at the Earth's surface. 
type of convection in the Earth's mantle which was not known earlier.

The velocities of elastic waves in the asthenosphere are lower than in mantle lithosphere. The electrical conductivity in the asthenosphere is much higher than in a cool mantle lithosphere. Rises by $\sim 100 \mathrm{~km}$ of the low-velocity and high conductivity layer (the asthenosphere) have been found beneath the regions of strong recent crustal uplift. They occur, e.g. beneath the Tien Shan mountains (Roecker et al., 1993) and the elevated area to the east of Lake Baikal (Kieselev and Popov, 1992; Gao et al., 1994). The formation of high mountains and plateaus during the last several million years required destruction of several tens percent of the whole volume of mantle lithosphere on the continents. This is the most powerful process in continental lithosphere.

\section{STRONG EXTENSION AND COMPRESSION OF THE LITHOSPHERE AT THE EPOCHS OF ITS SOFTENING; DESTRUCTION OF THE LOWER CRUST IN FOLD BELTS}

Large forces are acting along the lithospheric layer (Zoback, 1992). Due to its high strength, they produce no significant horizontal deformations over most of continental areas. However, large inelastic deformations of the lithosphere from time to time arise in some regions. Lithospheric extension by $1.2-2$ times produces rift valleys, $3-8 \mathrm{~km}$ deep and $20-80 \mathrm{~km}$ wide during periods of time from several million years to several tens of million years (Ziegler, 1992). Typical examples are the Kongo rift in East Africa and numerous rifts in the Basin and Range Province in the western United States. Such structures cover a small fraction $\left(\sim 10^{-2}\right)$ of the intracontinental areas and are widespread in the transitional zones from the continents to deep water oceanic basins. Compression of continental crust by 2-4 times in regions, 100$200 \mathrm{~km}$ wide, evolves during 1-10 million years and results in the formation of fold belts such as the Alps, Urals and Appalachians which are characterized by strong folding and thrusting of sediments and underlying crystalline crust (e.g. Coward et al.,
1989). The occurrence of these rapid deformations can be explained by strong softening of the lithospheric layer due to infiltration of surficially active fluids the asthenosphere.

Compression of the crust in fold belts results in a strong increase in crustal thickness. Since the crust is lighter than the underlying mantle, at constant density, thickening of the crust should produce the crustal uplift with a formation of high mountains. This is a popular explanation of mountain building (Miyashiro et al., 1982). However, it appears that after the end of strong compression, the Earth's crust in fold belts usually remained near to sea level (Artyushkov, 1983). This was typical of the Alps, Carpathians, Urals and many other regions. High mountains were formed later: $\sim 10-100$ million years after the end of compression.

The absence of strong uplift at the epochs of compression indicates that the same time a density increase occurred in the crust (Fig. 6). Its origin can be explained as follows. An increase in pressure is known to facilitate the formation of dense garnet granulites and eclogites from basalts. In a thickened crust basaltic rocks subside to a larger depth where the pressure is higher. Their rapid transformation into denser rocks is possible only in a presence of fluids. Strong compression of the crust arises when the lithosphere is softened by their infiltration. In a presence of fluids, rapid formation of dense rocks in the lower crust becomes also possible at an increased

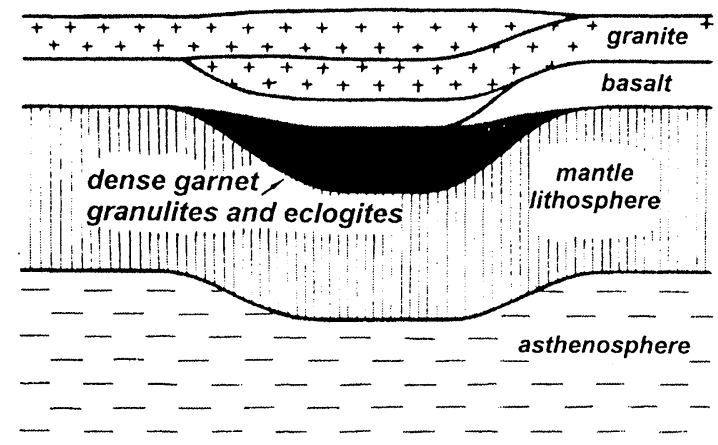

FIGURE 6 Formation of garnet granulites and eclogites in the lower crust at the epochs of strong compression of the lithosphere with thickening of the crust in fold belts. These dense rocks maintain the surface of a thickened crust at a low altitude. 
pressure. This is why, strong compression of the Earth's crust in fold belts and density increase in its lower part occur synchronously.

The density of eclogites $3500-3600 \mathrm{~kg} \mathrm{~m}^{-3}$ is larger than that of the underlying mantle $\left(3350 \mathrm{~kg} \mathrm{~m}^{-3}\right)$. At the epochs of compression, numerous blocks of these dense rocks delaminate from the crust and sink deeply into the mantle (Fig. 7) which results in destruction of large volumes of continental crust in fold belts. This phenomenon is well known for many areas, e.g. for the Alps (Laubscher, 1990). The crust was shortened by 3-4 times in this region; however, its means present thickness is only $\sim 1.5$ times larger than the initial one. Hence one half of the total crustal volumes at least was destroyed in the process of compression.

\section{ORIGIN OF SINKING OF UPPER CRUSTAL ROCKS INTO THE MANTLE AND THEIR RAPID RETURN TO THE CRUST}

In some continental areas blocks of rocks which were originally near to the Earth's surface contain minerals that grow only at high pressure at a depth $\geq 100 \mathrm{~km}$ : diamond, coesite, which is a high pressure modification of quartz, and others. They occur, e.g. in the Western Alps, north-western Kazakhstan and Eastern China. A presence of these minerals shows that sedimentary rocks which are lighter than the lower crust and the mantle subsided to large depth into the mantle and then emerged rapidly back to the crust. In a case of slow uplift, diamond and coesite would have transformed to graphite and quartz.

The mechanism of subsidence of light rocks of continental crust to a large depth, and especially of their rapid return to the surface is a major problem in the solid Earth's sciences. It has been suggested that continental crust of oceanic margins could be pulled down to $\geq 100 \mathrm{~km}$ by dense plates of oceanic lithosphere sinking (subducting) into the mantle (Chopin, 1987). However, coesite in the Alps was formed 60 million years after the end of subduction of oceanic crust. It cannot be also understood, why

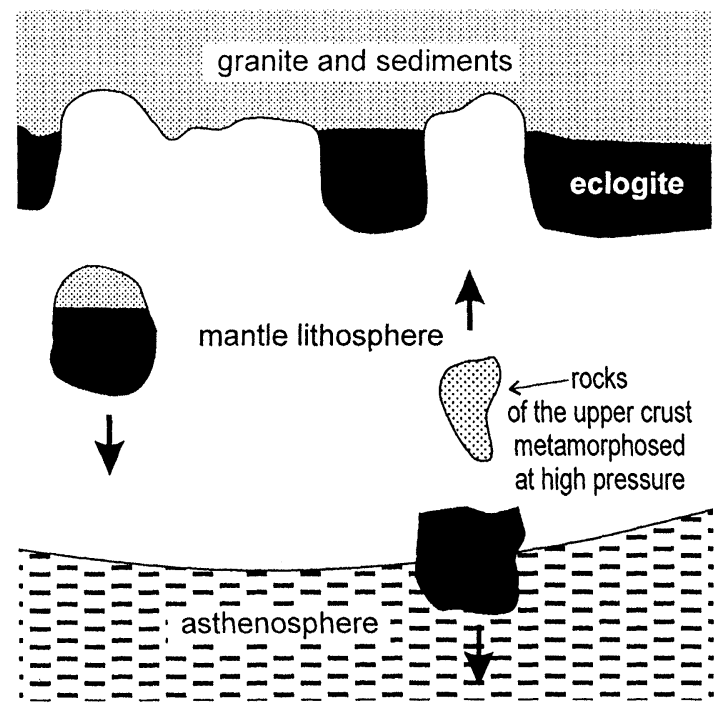

FIGURE 7 Sinking of blocks of dense eclogite into the mantle lithosphere at the epochs of lithospheric softening and strong compression of the crust in fold belts. Delamination of minor blocks of light rocks of the upper crust with high pressure minerals (diamond and coesite), which were formed at a large depth, and their rapid ascent through the mantle lithosphere to the crust.

sedimentary rocks emerged very rapidly from a depth $\geq 100 \mathrm{~km}$ through a high viscosity mantle and crust.

As suggested by Artyushkov, Hofmann and Korikovsky, the occurrence of high-pressure minerals in crustal rocks at the Earth's surface can be explained in another way. Large blocks of heavy eclogite sink into the mantle at the epochs of compression in fold belts (Fig. 7). Some of them curry down smaller blocks of upper crustal rocks which are attached to eclogite. These light blocks delaminate from eclogite at a depth $\geq 100 \mathrm{~km}$ and emerge back to the crust through a denser mantle lithosphere preserving diamonds and coesites which were formed at a large depth. Rapid uplift of light blocks is ensured by a strong temporary drop of mantle viscosity at the epochs of compression in fold belts.

\section{MECHANISM OF MOUNTAIN BUILDING IN FOLD BELTS}

After the end of strong compression of the crust in fold belts, large volumes of dense garnet granulites 
and eclogites with densities $3300-3600 \mathrm{~kg} \mathrm{~m}^{-3}$ still remain in the lower part of a thickened crust. According to high velocities of elastic waves, a layer of such rocks, $\sim 20 \mathrm{~km}$ thick, exists at a depth $40-$ $60 \mathrm{~km}$ in many regions, e.g. in the Urals (Druzhinin et al., 1997) and south-western Ukraine. The density of asthenosphere is considerably lower: $\sim 3200 \mathrm{~kg} \mathrm{~m}^{-3}$. When convective replacement of mantle lithosphere by the asthenosphere takes place and the asthenosphere emerges to the base of the crust, dense rocks delaminate from the crust and sink into the asthenosphere (Fig. 8). This can produce an additional crustal uplift to $\sim 2 \mathrm{~km}$. Replacement by the asthenosphere of a thick and dense mantle lithosphere gives rise to a crustal uplift of similar scale. These two effects can ensure the formation of mountains with a mean altitude up to $\sim 4 \mathrm{~km}$. Individual peaks can be of course considerably higher.

\section{STRONG IRREGULARITY IN TIME OF CRUSTAL MOVEMENTS ON THE CONTINENTS; NON-LINEAR PHENOMENA ASSOCIATED WITH THESE MOVEMENTS}

It is commonly believed that during the last $\sim 1.5$ billion years the crustal movements on the continents occurred in the same way as at present. Actually, the rate of crustal subsidence and uplift exhibits strong variations in time-by two orders of magnitude at least. Rapid crustal subsidence produced deep water basins during $\sim 1$ million years, while slow subsidence proceeded before and after these short events for $\geq 100$ million years. High mountains have been formed in many areas during the last $\sim 5$ million years, while during the preceding $\sim 200$ million years the crustal uplift was much slower. Short episodes of strong compression and extension of the lithosphere are interrupted by much longer periods of stability.

Rapid crustal movements in continental areas have a high intensity and produce large changes in the lithospheric structure and rheological properties, which results in strong non-linear effects. Delamination of the lower part of the lithosphere decreases the

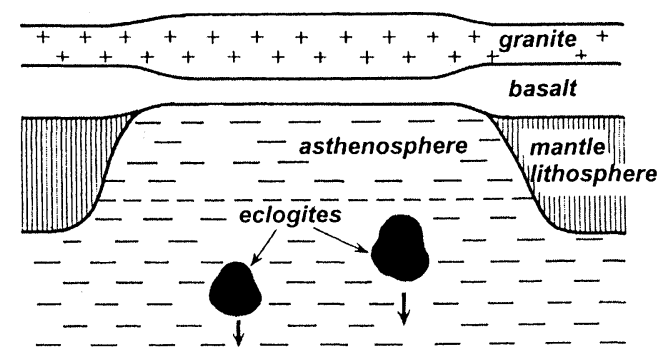

FIGURE 8 Emergence of light asthenosphere to the base of the crust with sinking of dense eclogites into the asthenospheric layer. This produces a strong uplift of the overlying crust and mountain building at the Earth's surface.

lithospheric thickness. This increase the stresses in the lithosphere which are due to the forces acting along this layer. The rate of strain in rocks of the crust and mantle depends non-linearly on the deviatoric stresses $\sigma$. The effective viscosity is proportional to $\sigma^{\mathrm{n}}$, and for most rocks $n=1-2$. In addition, tensile stresses enhance infiltration of fluids into the lithosphere which facilitates its softening and increases the thickness of the delaminated layer. Compressive stresses can produce an opposite effect, thus precluding replacement of a thick layer of mantle lithosphere by the asthenosphere.

Strong extension of the lithosphere in rift valleys and compression in fold belts are accompanied by brittle deformations which strongly decrease the strength and effective viscosity of this layer. However, the changes in thickness of the crust $(h)$ due to its extension and compression produce additional forces in the lithosphere which are proportional to $h^{2}$ (Artyushkov, 1983). These internal forces are compressive in a case of lithospheric extension in rift valleys and tensile in fold belts where compression of this layer takes place. In both cases, they oppose the deformations under external forces. The deformations cease when the internal forces balance the external ones.

\section{CONCLUSIONS}

According to popular ideas, vertical crustal movements on the continents-the crustal subsidence and 
uplift result from horizontal motions of lithospheric plates (e.g. McKenzie, 1978; Miyashiro et al., 1982). In most cases, these movements are actually independent of plate drift and result from deep seated processes in the crust and mantle (Artyushkov, 1983). The basic phenomenon is infiltration of fluids from the asthenosphere into the lithospheric layer. This triggers the transformation of basalts into denser rocks with the crustal subsidence and the formation of sedimentary basins. Another effect is a strong decrease in the lithospheric viscosity. This allows convective instability at the lithosphere-asthenosphere boundary with strong uplift of the overlying crust. In regions with soft lithosphere, rapid inelastic extension or compression of this layer occurs which results in formation of deep elongated basins-rift valleys and of fold belts with strongly shortened crust. The above phenomena produce large changes in the lithospheric structure and stresses acting in this layer, which results in some strong non-linear effects.

\section{References}

Artyushkov, E.V. (1983) Geodynamics (Elsevier, Amsterdam). Artyushkov, E.V. (1993) Physical Tectonics (Nauka, Moscow).

Artyushkov, E.V. and Baer, M.A. (1986) "Mechanism of formations of hydrocarbon basins: the West Siberia, Volga-Urals, TimanPechora basins and the Permian Basin of Texas", Tectonophysics 122, 247-281.

Artyushkov, E.V. and Baer, M.A. (1987) "Mechanism of formation of the oil and gas basins of the Persian Gulf", Int. Geol. Rev. 29, 218-233.

Artyushkov, E.V. and Hofmann, A.W. (1998) "The Neotectonic crustal uplift on the continents and its possible mechanisms. The case of Southern Africa", Surv. Geophys. 19, 369-415.

Artyushkov, E.V. and Mörner, N.-A. (1997) "Rapid formation of steep flexures under sedimentary basins-an indication for a temporary loss of rigidity of the lithospheric layer", Doklady, Earth Sci. Sect. 356, 382-386.

Artyushkov, E.V. and Mörner, N.-A. (1998) "Steep bending of continental lithosphere without its stretching or plate collision: an indication for lithospheric failure", Terra Nova 10, 101-105.
Artyushkov, E.V., Baer, M.A., Letnikov, F.A. and Ruzhich, V.V. (1991) "On the mechanism of graben formation", Tectonophysics 197, 95-115.

Burov, E.B. and Diament, M. (1995) "The effective elastic thickness (Te) of continental lithosphere: what doest it really mean?", J. Geophys. Res. 100, 3905-3927.

Chopin, C. (1987) "Very high pressure metamorphism in the western Alps: Implication for subduction of continental crust", Phil. Trans. R. Soc. Lond. A 321, 183-197.

Coward, M.P., Dietrich, D., (1989) Alpine Tectonics (Geol. Soc. Lond. Spec. Publ. Vol. 45.

Druzhinin, V.S., Kashubin, S.N., Kashubina, T.V., Kolmogorova, V.A., Parygin, G.V., Rybalka, A.V. and Tiunova, A.M. (1997) "The main features of the interface between the crust and the upper mantle in the Middle Urals (in the vicinity of the deep drillhole SG-4)", Tectonophysics 269, 259-268.

Gao, S., Davis, P.M., Liu, M.H., Slack, P.D., Zorin, Y.A., Logachev, N.A., Kogan, M.B., Burkholder, P.D. and Meyer, R.P. (1994) "Asymmetric upwarp of the asthenosphere beneath the Baikal rift zone, Siberia", J. Geophys. Res. 96, 15319-15330.

Kieselev, A.I. and Popov, A.M. (1992) "Asthenospheric diapir beneath the Baikal rift: petrological constraints", Tectonophysics 208, 287-295.

Laubscher, H. (1990) "The problem of the Moho in the Alps", Tectonophysics 182, 9-20.

Li Jijun, et al. (1995) The Uplift of Quinghai-Xizang (Tibet) Plateau and Global Change (Lanzhou University Press, Lanzhou).

McKenzie, D. (1978) "Some remarks on the development of sedimentary basins", Earth Planet. Sci. Lett. 40, 25-32.

Miyashiro, A., Aki, K. and Sengör, A.M.C. (1982) Orogeny (Wiley, Chichester).

Pisotsky, B.I. (1999) "Expression of the processes of a reducing fluidization in hydrocarbon provinces and role of mantle components in genesis of hydrocarbons" Rehabilitation Thesis (Moscow, VNIIGeosystems), in Russian.

Rebinder, P.A. and Venström, E.K. (1937) "An influence of a medium and adsorbed layers on a plastic flow of metals", Proc. OMEN, Phys. Ser. 4(5), 531-550.

Roecker, S.W., Sabitova, T.M., Vinnik, L.P., Burmakov, Y.A., Golvanov, M.I., Mamatkanova, R. and Minurova, L. (1993) "Three-dimensional elastic wave velocity structure of the western and central Tien Shan", J. Geophys. Res. 98, 15779-15795.

Rutter, E.H. (1983) "Pressure solution in nature, theory and experiment", J. Geol. Soc. Lond. 140, 725-740.

Ziegler, P.A. (1992) "Geodynamics of rifting, v. I. Case history studies on rifts: Europe and Asia", Tectonophysics 208.

Zoback, M.L. (1992) "First- and second-order patterns of stress in the lithosphere: the world stress map project”, J. Geophys. Res. 97, 11703-11728 


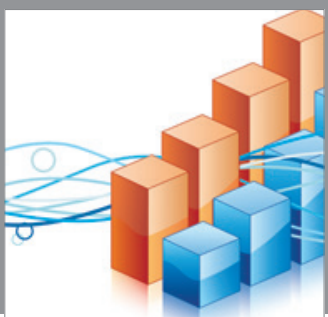

Advances in

Operations Research

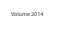

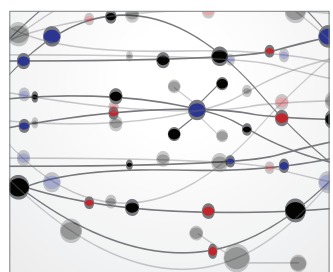

\section{The Scientific} World Journal
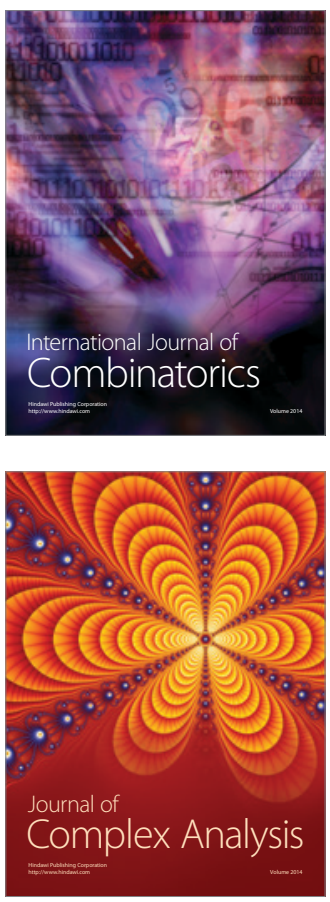

International Journal of

Mathematics and

Mathematical

Sciences
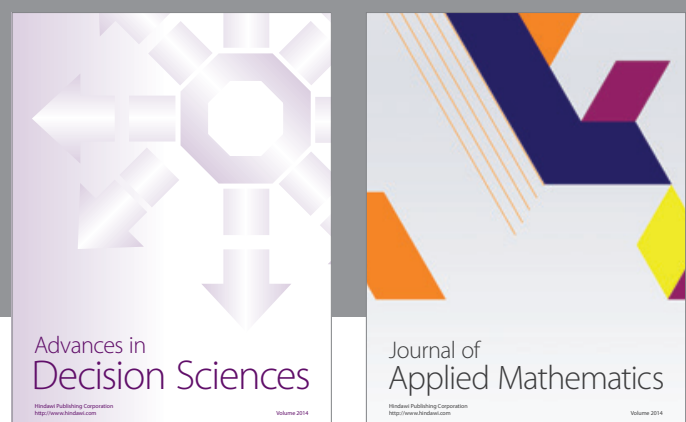

Journal of

Applied Mathematics
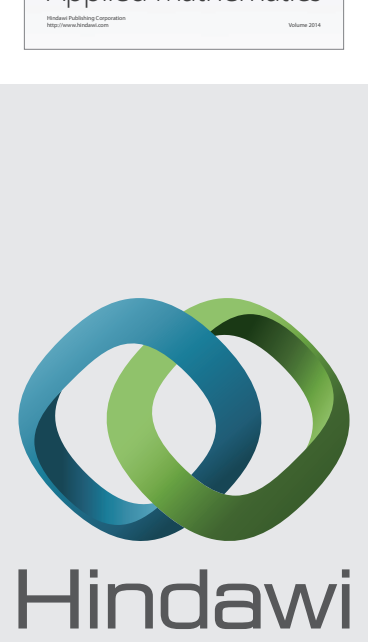

Submit your manuscripts at http://www.hindawi.com
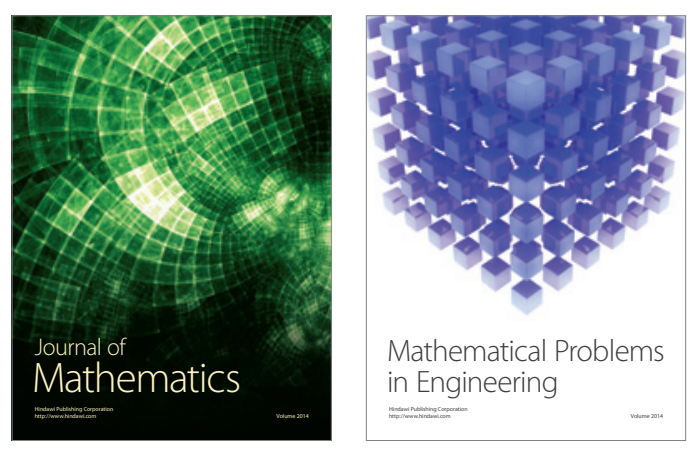

Mathematical Problems in Engineering
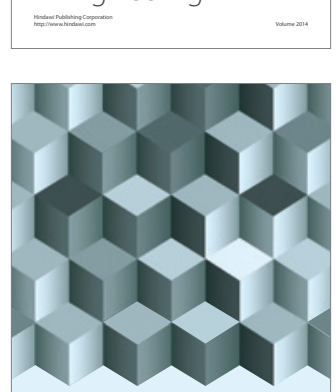

Journal of

Function Spaces
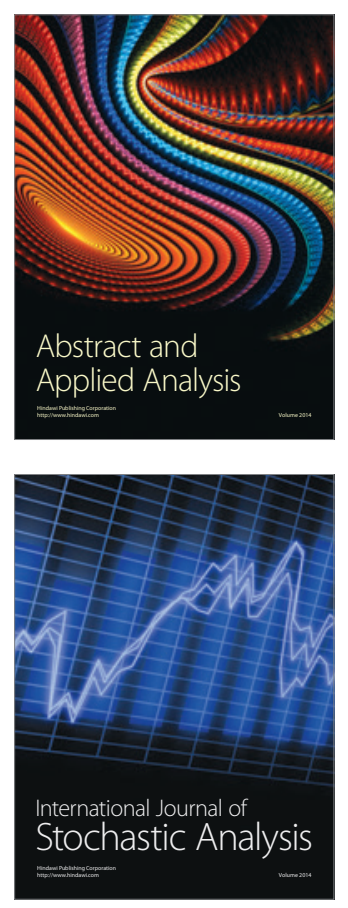

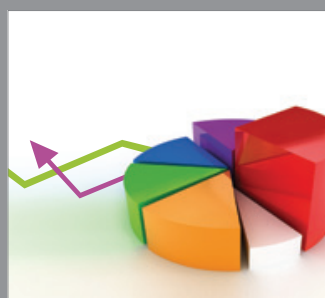

ournal of

Probability and Statistics

Promensencen
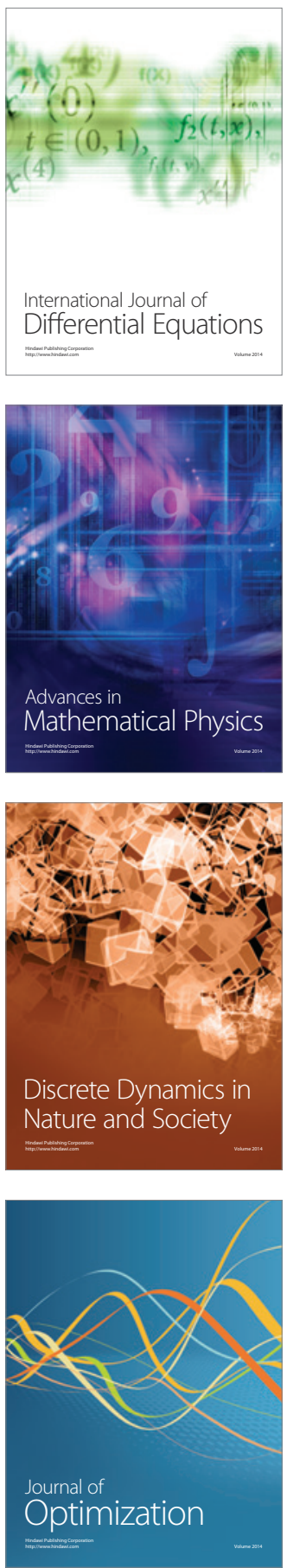